\title{
Deceased Donor with Diabetic Nephropathy: Case Report of Four Kidney Recipients
}

\author{
Visona I* and Franco MF \\ Department of Pathology, School of Medicine, Federal \\ University of Sao Paulo, Brazil \\ *Corresponding author: Visona I MD, MSc, \\ Departamento de Patologia, Universidade Federal de São \\ Paulo, Escola Paulista de Medicina (UNIFESP), Brazil
}

Received: April 11, 2017; Accepted: May 10, 2017;

Published: May 22, 2017

\begin{abstract}
Diabetes Mellitus is a disease of increasing incidence, estimated at about $5 \%$ of the world's population, mostly in developing countries. Type II diabetes, formerly known as adult diabetes, comprises about $90 \%$ of all cases, with a concentration in the 45-64 years old group, usually associated with obesity. Frequently, kidneys from donors with diabetes have being refused for graft due to the possibility of presenting diabetic nephropathy, one of the main complications of this disease. However, with the increased need of organs for transplantation, the demand for kidneys from potential deceased donors has also increased and, even older donors or with comorbidities such as hypertension or diabetes, may have kidneys considered viable for donation. The aim of the present work is to report the different outcomes in four kidney recipients, whose donors had diabetic nephropathy proven by biopsy.
\end{abstract}

Keywords: Kidney transplantation; Diabetes mellitus; Deceased donor; Biopsy

\section{Case Presentation}

\section{First donor}

A 41-year-old man, victim of ischemic stroke, with type II Diabetes mellitus (DM) and Hypertension, became a deceased donor, with final creatinine value of $1.5 \mathrm{mg} / \mathrm{dl}$ and cold ischemia time of 36 hours. A pre-implant needle biopsy was performed, revealing difuse and nodular glomerulosclerosis, charaterístic of diabetic glomerulopathy of Kimmelstiel-Wilson, besides moderate acute tubular injury and arteriolar hyalinosis.

\section{Second donor}

A 62-year-old man, with type II DM, alcoholic for many years, victim of traumatic brain injury, became a deceased donor, with final creatinine value of $1.2 \mathrm{mg} / \mathrm{dl}$ and cold ischemia time of 20 hours. An isolated blood glucose dosage revealed $240 \mathrm{mg} / \mathrm{dl}$. A pre-implant needle biopsy was performed, showing the same alterations as observed in the first donor's biopsy.

\section{First recipient}

A 68-year-old man, with unknown primary renal disease, on hemodialysis for five years, received a kidney from the first donor. Because of a delayed graft function (DGF), two indication-biopsies were performed (in the $11^{\text {th }}$ and $18^{\text {th }}$ days) revealing nodular diabetic glomeruloesclerosis of Kimmelstiel-Wilson. The patient had a prolonged hospitalization due to an important urinary bacterial infection and systemic cytomegalovirosis and was discharged on the $45^{\circ}$ day, with a creatinine value of $3.6 \mathrm{mg} / \mathrm{dl}$. There was a persistently deteriorating renal function with recurrent hospitalizations for edema, proteinuria and uremia and little response to diuretics, requiring dialysis. After five months of transplant, a Doppler ultrasound showed renal graft artery stenosis, this was corrected with a stent. During the next 7 months, the medium creatinine value was $4.0 \mathrm{mg} / \mathrm{dl}$ and after 1 year and 1 month the renal artery stenosis recurred. It was decided to give up with the graft.

\section{Second recipient}

A 47-year-old woman, with hypertension as primary renal disease and hemodialysis for three years was prioritized for transplantation due to vascular access difficulties and received a kidney from the first donor. The graft has never functioned and she remained anuric, requiring hemodialysis. An indication-biopsy of the graft biopsy done on the $18^{\text {th }}$ day, and showed nodular diabetic glomeruloesclerosis of Kimmelstiel-Wilson. On the $20^{\text {th }}$ postoperative day, she presented with hematoma at the central access puncture site, evolving with coagulopathy and shock that was reversed after transfusions. A conservative conduct was adopted and the immunosuppressive suspended. The graft was removed in the $50^{\text {th }}$ day post-transplantation and she returned to hemodialysis.

\section{Third recipient}

A 53-year-old woman, with hypertension as primary renal disease and on hemodialysis during 11 years was prioritized for transplant because of many positive previous cross-matchs and also because of poor vascular access for dialysis. She received a kidney from the second donor and was discharged on the $11^{\text {th }}$ postoperative day with a creatinine value of $7.07 \mathrm{mg} / \mathrm{dl}$, progressively decreasing. At three months post-transplantation, a subnephrótic proteinuria started on. During the first year she maintained a good renal function, with creatinine values between 1.4 and $1.9 \mathrm{mg} / \mathrm{dl}$. Graft biopsies were performed on the $8^{\circ}$ day, at five months and with one year and three months post-transplantation, all of them with the diagnosis of nodular diabetic glomeruloesclerosis of Kimmelstiel-Wilson. The patient progressed with excellent graft function until the present date (three years and five months post-transplantation) and the last creatinine value was $1.3 \mathrm{mg} / \mathrm{dl}$.

\section{Fourth recipient}

A 53-year-old man, whose primary renal disease was Membranous Glomerulonephritis, had been on hemodialysis for 10 months. He 


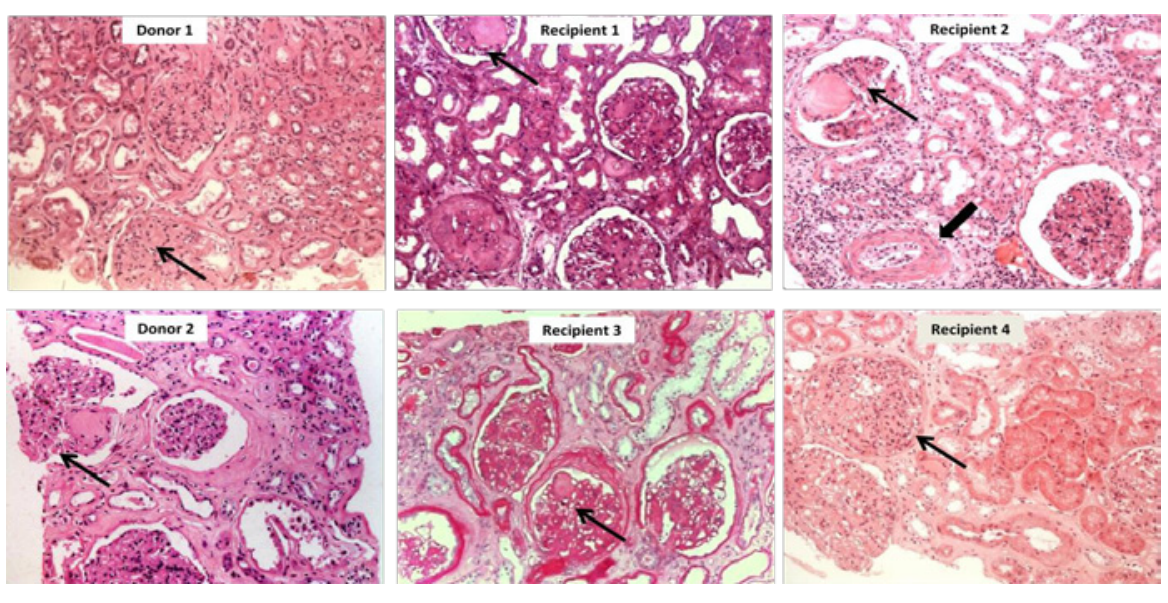

\begin{abstract}
Figure 1: Histological sections of the biopsies from donors (preimplantation) and the correspondent recipients. Diabetic nephropathy with glomeruli showing the classical Kimmelstiel-Wilson nodules (thin arrow) and signs of tubulointerstitial chronicity with arteriolar hyalinosis, in both donors and recipients' biopsies. The product of explants from the second recipient also shows Acute Vascular Rejection demonstrated by intimitis (thick arrow) (HE, 200x).
\end{abstract}

received a kidney from the second donor and evolved with DGF, with a creatinine value of $9.8 \mathrm{mg} / \mathrm{dl}$ in the $15^{\text {th }}$ postoperative day, decreasing. A subnephrotic proteinuria began at 10 months post-transplantation. During the first year he maintained a good renal function (creatinine values between 1.3 and $2.5 \mathrm{mg} / \mathrm{dl}$ ). Graft's biopsies were performed on the $13^{\text {th }}$ day, at 30 days and with one year póst-transplantation, with the diagnosis of nodular diabetic glomeruloesclerosis of KimmelstielWilson. In the second year he presented with gradual worsening of the function, requiring hemodialysis, with graft loss at one year and nine months (Figure1).

\section{Discussion}

Diabetes Mellitus is a disease of increasing incidence, estimated at about $5 \%$ of the world's population, mostly in developing countries. Type II diabetes, formerly known as adult diabetes, comprises about $90 \%$ of all cases, with a concentration in the age group of 45-64 years and usually associated with obesity [1]. Frequently, kidneys from donors with DM have being refused for graft due to the possibility of presenting diabetic nephropathy, one of the main complications of this disease. However, with the increased need of organs for transplantation, the demand for kidneys from potential deceased donors has also increased and, even older donors or with comorbidities such as hypertension or diabetes, may have kidneys considered viable for donation [2]. The aim of the present work is to report the different outcomes in four kidney recipients, whose donors had diabetic nephropathy proven by biopsy.

Despite the shorter survival of grafts from deceased diabetic donors (DDD), marginal donor recipients benefit from lower mortality when compared to those awaiting dialysis [3]. The structural quality of these kidneys can be evaluated by histological criteria through preimplant biopsy, which is however routinely performed only in a few transplant centers. One study shows that the preimplantation biopsy allows a decision on the use of the organ in the recipient and predicts graft survival, since severe chronic lesions can mean short graft survival [4]. There are few reported cases of renal transplantation between diabetic donors and non-diabetic recipients and even less cases involving donors who, at the time of implantation, already had diabetic nephropathy documented by biopsy. A study of 2,300 kidney DDD recipients concluded that the survival of these grafts was significantly lower (17\%) when compared to non-diabetic donor grafts, but the absolute difference was small [5]. It also concluded that there was no statistical difference in the mortality of these patients. In a study with less patients, 42 DDD recipients showed a slight elevation in the mean creatinine value and a significant increase in the frequency of proteinuria [6]. A more recent work concluded that, after six months of transplantation, seven of nine patients with DDD grafts (77\%) showed creatinine values from 1.3 to $2.4 \mathrm{mg} / \mathrm{dl}$, meaning a good graft function [7].

It was not the purpose of this study to understand the reasons that led to the decision to implant kidneys having so severe morphological changes on the preimplantation biopsies. The present study taught us that: 1) Despite the histological aspect, one of the four recipients remained with functioning kidney after three years and six months, until now maintaining excellent function. 2) Behind the structural similarities of the biopsies, there must be other factors that influence the performance of the graft, perhaps related to its functional reserve. 3) Proteinuria appears as a marker for advanced diabetic glomerulopathy, as three of our four patients had subnephrotic, beginning at least from 2 months post-transplantation.

\section{References}

1. Adolfo Milevich. Diretrizes da Sociedade Brasileira de Diabetes. 2015-2016.

2. Perico N, Ruggenenti $P$, Scalamogna $M$, Remuzzi G. Tackling the shortage of donor kidneys: how to use the best that we have. Am J Nephrol. 2003; 23: 245-259.

3. Ojo AO, Hanson JA, Meier-Kriesche $\mathrm{H}$, Okechukwu CN, Wolfe RA, Leichtman $A B$, et al. Survival in recipients of marginal cadaveric donor kidneys compared with other recipients and wait-listed transplant candidates. J Am Soc Nephrol. 2001; 12: 589-597.

4. Hofer J, Regele H, Böhmig GA, Gutjahr G, Kikić Z, Mühlbacher F, et al. Preimplant biopsy predicts outcome of single-kidney transplantation independent of clinical donor variables. Transplantation. 2014; 97: 426-432.

5. Ahmad M, Cole EH, Cardella CJ, Cattran DC, Schiff J, Tinckam KJ, et al. Impact of deceased donor diabetes mellitus on kidney transplant outcomes: a propensity score-matched study. Transplantation. 2009; 88: 251-260. 
6. Becker YT, Leverson GE, D'Alessandro AM, Sollinger HW, Becker BN. Diabetic kidneys can safely expand the donor pool. Transplantation. 2002 74: $141-145$
7. Wolters HH, Brockmann JG, Diller R, Suwelack B, Krieglstein CF, Senninger N. Kidney transplantation using donors with history of diabetes and hypertension. Transplant Proc. 2006; 38: 664-665.
Austin J Nephrol Hypertens - Volume 4 Issue 1 - 2017

ISSN : 2381-8964 | www.austinpublishing group.com

Visona et al. (C) All rights are reserved
Citation: Visona I and Franco MF. Deceased Donor with Diabetic Nephropathy: Case Report of Four Kidney Recipients. Austin J Nephrol Hypertens. 2017; 4(1): 1064. 